\title{
Inclusão do ovo desidratado em rações peletizadas ou fareladas para frangos de corte ${ }^{1}$
}

\author{
${ }_{1}^{1}$ Parte da dissertação de Mestrado da primeira autora, apresentada ao PPGZ/CCA/UFPB, Areia - PB. \\ 2 Doutorado Integrado em Zootecnia, PIDZ/CCA/UFPB/UFRPE/UFC, Areia - PB. Bolsista da Capes. \\ ${ }^{3}$ DAP/CFT/UFPB, Bananeiras - PB e PPGZ - CCA/UFPB, Areia, PB. Bolsista do PQ-CNPq. \\ ${ }^{4}$ PPGZ/CCA/UFPB, Areia - PB. Bolsista de PQ-CNPq. \\ ${ }^{5}$ Doutorado em Zootecnia da FMVZIUNESP, Botucatu, SP. Bolsista FAPEAL.
}

Elisanie Neiva Magalhães Teixeira², José Humberto Vilar da Silva ${ }^{3}$, Fernando Guilherme Perazzo Costa ${ }^{4}$, Marcelo Luís Gomes Ribeiro², Daniel de Magalhães Araujo ${ }^{5}$, José Jordão Filho²

RESUMO - Um experimento foi realizado para estudar o efeito da forma física da ração (farelada ou peletizada) e da inclusão de ovo desidratado na ração até os 21 dias de idade sobre o desempenho e as características de carcaça de frangos de corte da linhagem Cobb-500 aos 42 dias de idade. As aves com 1 dia de vida e peso médio de 42,94 \pm 0,51 g foram alojadas em boxes de $1,0 \times 1,5 \mathrm{~m}$. O delineamento adotado foi o inteiramente casualizado em esquema fatorial com dois níveis de ovo desidratado (0 e 0,5\%) e duas formas físicas da ração (farelada e peletizada), resultando em quatro rações com 18 repetições de 16 aves durante as fases de 1 a 7; de 8 a 21; de 22 a 33 e de 34 a 42 dias de idade. A inclusão de 0,5\% de ovo desidratado nas rações pré-inicial e inicial não influenciou o desempenho, porém, a ração peletizada melhorou o desempenho dos frangos de corte aos 42 dias de idade. A peletização da ração também melhorou o rendimento de peito, do Pectoralis minor e do filé de peito em relação ao peso da carcaça e aumentou os pesos do proventrículo e do intestino delgado, enquanto a ração farelada aumentou o peso da moela.

Palavras-chave: alimento alternativo, desempenho, carcaça

\section{Inclusion of the dehydrated egg in diets in mash and pelleted form for broiler chicks}

\begin{abstract}
The experiment was carried out to evaluate the effect of physical form diet (mash or pelleted) and inclusion of dehydrated egg (DEGG) up to 21 days of age on the performance and carcass characteristic of Cobb-500 strain of broiler chicks at 42 days of age. The birds with average weight of $42.94 \pm 0.51 \mathrm{~g}$ were allotted in pens of $1.0 \mathrm{x} 1.5 \mathrm{~m}$. The experimental design was completely randomized in factorial arrangment with two levels of DEGG (0 and 0.5\%) and two physical form of diet (mash and pellet), resulting in four diets with 18 replicates of 16 birds during the phases from 1 to $7 ; 8$ to 21;22 to 33 and 34 to 42 days of age. The DEGG inclusion in the pre initial and initial diets did not influenced the performance, but the pelleted diet improved the performance of for broiler chicks up to 42 days. The pelleted diet also improved breast, Pectoralis minor and fillet of breast yields in relationship to carcass weight, and increased the proventriculus and small intestine weights, while the mashed diet increased the gizzard weight.
\end{abstract}

Key Words: alternative feeds, carcass, performance

\section{Introdução}

O ovo integral é ótima fonte protéica e energética, rica em aminoácidos essenciais, componentes fundamentais na nutrição inicial de aves. Teixeira et al. (2005) constataram que o ovo desidratado apresenta 51,54\% de PB, $4.278 \mathrm{kcal}$ de EMAn e 8,53 de cinzas. À eclosão, o resíduo da gema constitui $20 \%$ do peso corporal dos pintos e pode ser considerado fonte imediata de energia e proteína para mantença e crescimento (Noy \& Sklan, 2001). O fornecimento do ovo desidratado nas primeiras 24 horas de alimentação melhora o peso vivo de pintinhos (Ribeiro et al., 2006a) e a possível explicação para esse resultado é o predomínio do metabolismo energético de lipídios sobre o dos carboidratos na fase pós-eclosão (Dibner, 1997).

O ovo é fonte de imunoglobulinas e pode contribuir para a nutrição e profilaxia em aves e suínos. Silva et al. (2006), em experimento com pintinhas leves e semipesadas alojadas em dois ambientes (um limpo e outro sujo), concluíram que a inclusão de $0,6 \%$ de ovo desidratado em dietas para a fase pré-inicial pode melhorar o desempenho de aves alojadas em ambiente convencional. 
O processo de peletização das rações, por sua ação mecânica e térmica, melhora a digestibilidade dos nutrientes (Vargas, 2001), inclusive a dos carboidratos, que é aumentada uma vez que o processo provoca a desnaturação dos grânulos de amilose e amilopectina, facilitando a ação enzimática (Moran, 1987).

A peletização contribui para reduzir a contaminação da ração minimizando o risco de surgimento de infecções por Escherichia coli (McCapsm et al., 1989; Nilipour, 1993).

De acordo com Nilipour (1993), outras vantagens atribuídas à peletização das dietas são a prevenção da seletividade dos ingredientes e da segregação de ingredientes durante o transporte e manejo, a redução da pulverulência da ração e a melhora da eficiência alimentar, pois reduz o tempo gasto para o consumo.

Neste trabalho objetivou-se avaliar o efeito da forma física da ração (farelada ou peletizada) e do fornecimento de ovo desidratado ( 0 e $0,5 \%$ ) nos primeiros 21 dias de idade sobre o desempenho e as características da carcaça de frangos de corte aos 42 dias de idade.

\section{Material e Métodos}

O experimento foi realizado no Setor de Avicultura do Centro de Formação de Tecnólogos (CFT), Campus III da Universidade Federal da Paraíba (UFPB), localizado em Bananeiras, microrregião do Brejo Paraibano, no período de julho a setembro de 2005.

Utilizou-se um lote misto de 1.152 pintos da linhagem Cobb-500, alojados em boxes de 1,0×1,5 m. As médias de temperatura e umidade relativa do ar mínimas e máximas no interior do galpão, registradas em aparelho termohigrômetro em dois períodos diários, às 8 e às $16 \mathrm{~h}$, foram, respectivamente, de 25 e $30^{\circ} \mathrm{C}$ e de 95 e $43 \%$. Durante a fase inicial, as aves foram mantidas sob luz contínua (luz natural + artificial).

O delineamento utilizado foi o inteiramente casualizado em esquema fatorial $2 \times 2$, composto de dois níveis de ovo desidratado (0 ou $0,5 \%)$ e duas formas físicas da ração (farelada ou peletizada), resultando em quatro tratamentos com 18 repetições de 16 aves. Foram estudadas as fases de 1 a $7 ; 8$ a 21; 22 a 33 e de 34 a 42 dias de idade.

As dietas, à base de milho e farelo de soja, foram formuladas segundo recomendações de Rostagno et al. (2005) e continham 21,92\% de PB e $2.950 \mathrm{kcal}$ EMAn/kg para fase de 1 a 7 dias; 20,79\% de PB e $3.000 \mathrm{kcal} \mathrm{EMAn/kg} \mathrm{para}$ a fase de 8 a 21 dias; 19,41\% de PB e $3.100 \mathrm{kcal} / \mathrm{kg}$ EMAn para a fase de 22 a 33 dias e; $18,03 \%$ de PB e $3.150 \mathrm{kcal} \mathrm{EMAn/kg}$ para a fase de 33 a 42 dias de idade (Tabela 1 ).
Foram utilizados ovos descartados para o consumo humano, coletados diariamente no setor de Avicultura do CFT. Na quebra da casca, o conteúdo (gema + clara) foi pesado, colocado em bandejas e levado à estufa com ventilação forçada a $55^{\circ} \mathrm{C}$ durante 72 horas. Em seguida, o material pré-seco foi retirado, pesado, moído e armazenado em freezer para posterior utilização na formulação das rações experimentais. O produto foi utilizado na formulação das dietas somente mediante resultado negativo do teste de Salmonella ssp., realizado no Laboratório de Controle de Qualidade de Alimentos do Centro de Formação de Tecnólogos - CFT, segundo recomendações do Laboratório Nacional de Referência Animal - Lanara (1981). A composição aminoacídica do ovo desidratado em aminoácidos foi obtida de acordo com Norberg et al. (2004), enquanto a de EMAn e o teor de proteína foram analisados antes da realização deste experimento.

O processo de secagem do conteúdo dos ovos em baixa temperatura e durante tempo mais longo de exposição foi adotado com vistas a eliminar patógenos, inativar o ovomucóide, que pode ter atividade de inibir a tripsina, minimizar a formação da reação de Maillard, que eventualmente poderia reduzir a digestibilidade dos aminoácidos, e inativar imunoglobulinas e lizosima.

O ovo desidratado foi incluído no nível de 0,5\%, conforme sugestão de Ribeiro et al. (2006b), nas rações para as fases de 1 a 7 e de 8 a 21 dias para avaliação de seu efeito residual nas fases de 22 a 33 e de 34 a 42 dias de idade. A peletização das rações foi realizada em máquina peletizadora de 7 HP utilizando-se 0,3\% de lignosulfato (Melbond ${ }^{\circledR}$ ) como agente ligante de péletes.

As características de desempenho estudadas foram o peso vivo (PV), os ganhos de peso diário (GPD) e total (GPT), os consumos de ração diário (CRD) e total (CRT) e a conversão alimentar (CA) nos períodos de 1 a 2, de 1 a 4, 1 a 7, 1 a 14, 1 a 21,1 a 33 e 1 a 42 dias de idade.

Os ganhos de peso diário e total foram obtidos pela pesagem das aves aos 2, 4 e 7 dias de idade (fase pré-inicial) e aos 14, 21 (fase inicial), 33 e 42 dias de idade (fase de crescimento). Os pesos foram subtraídos do peso inicial e o resultado foi dividido pelo número de aves em cada parcela.

O consumo total (CTR) foi determinado pela diferença entre a quantidade de ração fornecida e as sobras dos baldes e dos comedouros em cada parcela experimental, enquanto o consumo diário (CDR) foi estimado pela relação entre o consumo total e o número de dias e de aves em cada parcela.

Aos 42 dias de idade, 36 aves por tratamento, com peso vivo de $\pm 10 \%$ do peso médio de cada parcela experimental, foram mantidas em jejum de 24 horas e abatidas para análise 
Tabela 1 - Composição química das rações experimentais ${ }^{1}$

Table 1 - Chemical composition of the experimental diets ${ }^{1}$

\begin{tabular}{|c|c|c|c|c|c|c|}
\hline \multirow{3}{*}{$\begin{array}{l}\text { Item } \\
\text { Ingrediente (Ingredient) }\end{array}$} & \multicolumn{6}{|c|}{ Ovo desidratado (Dehydrated egg) } \\
\hline & \multicolumn{2}{|c|}{1 a 7 dias } & \multicolumn{2}{|c|}{8 a 21 dias } & \multirow{2}{*}{$\frac{22 \text { a } 33 \text { dias }}{0,0}$} & \multirow{2}{*}{$\frac{34 \text { a } 42 \text { dias }}{0,0}$} \\
\hline & 0,0 & 0,5 & 0,0 & 0,5 & & \\
\hline Milho (Corn) & 56,233 & 55,934 & 58,35 & 58,682 & 61,309 & 65,300 \\
\hline Farelo de soja (Soybean meal) & 36,833 & 36,333 & 34,448 & 33,823 & 30,745 & 26,950 \\
\hline Calcário (Limestone) & 0,997 & 0,997 & 0,849 & 0,850 & 0,835 & 0,793 \\
\hline Fosfato bicálcico (Dicalcium phosphorus) & 1,897 & 1,904 & 1,845 & 1,849 & 1,657 & 1,509 \\
\hline Ovo desidratado ${ }^{2}$ (Dehydrated egg) & 0,000 & 0,500 & 0,000 & 0,500 & 0,000 & 0,000 \\
\hline DL-metionina (DL-methionine) & 0,253 & 0,25 & 0,237 & 0,235 & 0,243 & 0,222 \\
\hline L-lisina $\bullet \mathrm{HCl}($ L-lysine $\bullet H C L)$ & 0,182 & 0,179 & 0,184 & 0,183 & 0,235 & 0,249 \\
\hline Treonina (Threonine) & 0,000 & 0,000 & 0,06 & 0,059 & 0,061 & 0,074 \\
\hline Bicarbonato de sódio (Sodium bicarbonate) & 0,000 & 0,000 & 0,15 & 0,15 & 0,000 & 0,000 \\
\hline Óleo vegetal (Vegetable oil) & 2,500 & 2,500 & 2,872 & 2,662 & 3,829 & 3,846 \\
\hline Premix mineral ${ }^{3}$ (Mineral mix) & 0,050 & 0,050 & 0,050 & 0,050 & 0,050 & 0,050 \\
\hline Premix vitamínico ${ }^{4}$ (Vitamin mix) & 0,100 & 0,100 & 0,100 & 0,100 & 0,100 & 0,100 \\
\hline Cloreto de colina, $70 \%$ (Choline cloride) & 0,080 & 0,080 & 0,060 & 0,060 & 0,060 & 0,060 \\
\hline Sal (Salt) & 0,458 & 0,459 & 0,39 & 0,39 & 0,47 & 0,442 \\
\hline Anticoccidiano $^{5}$ (Anticoccidian) & 0,004 & 0,004 & 0,004 & 0,004 & 0,004 & 0,004 \\
\hline Pró-nutriente ${ }^{6}$ (Growth promoter) & 0,015 & 0,015 & 0,015 & 0,015 & 0,015 & 0,015 \\
\hline Antioxidante $^{7}$ (Antioxidant) & 0,010 & 0,010 & 0,010 & 0,010 & 0,010 & 0,010 \\
\hline Ligante de péletes ${ }^{8}$ (Pellet ligant) & 0,300 & 0,300 & 0,300 & 0,300 & 0,300 & 0,300 \\
\hline Inerte $^{9}$ (Inert) & 0,088 & 0,385 & 0,076 & 0,078 & 0,077 & 0,076 \\
\hline \multicolumn{7}{|l|}{ Composição química (Chemical composition) } \\
\hline $\mathrm{PB}, \%(C P)$ & 21,91 & 21,91 & 20,79 & 20,79 & 19,41 & 18,03 \\
\hline EM, kcal/kg (ME) & 2.950 & 2.950 & 3.000 & 3.000 & 3.100 & 3.150 \\
\hline $\mathrm{Ca}, \%$ & 0,988 & 0,988 & 0,884 & 0,884 & 0,824 & 0,763 \\
\hline P total, \% (Total P) & 0,703 & 0,701 & 0,664 & 0,662 & 0,616 & 0,579 \\
\hline P disponível, \% (Available P) & 0,466 & 0,466 & 0,450 & 0,450 & 0,411 & 0,380 \\
\hline Metionina total, \% (Total met) & 0,585 & 0,586 & 0,554 & 0,556 & 0,541 & 0,503 \\
\hline Metionina digestível, \% (Dig. met) & 0,555 & 0,556 & 0,525 & 0,521 & 0,514 & 0,478 \\
\hline Met + cys total, \% (Total met + cys) & 0,926 & 0,926 & 0,882 & 0,884 & 0,852 & 0,797 \\
\hline Met+cys dig., \% (Dig. met+cys) & 0,843 & 0,843 & 0,807 & 0,807 & 0,782 & 0,732 \\
\hline Lisina total, \% (Total lys) & 1,307 & 1,307 & 1,238 & 1,238 & 1,183 & 1,098 \\
\hline Lisina digestível, \% (Dig. lys) & 1,187 & 1,187 & 1,143 & 1,143 & 1,094 & 1,017 \\
\hline Treonina total, \% (Total thr) & 0,841 & 0,842 & 0,859 & 0,859 & 0,804 & 0,762 \\
\hline Treonina digestível, \% (Dig. thr) & 0,732 & 0,733 & 0,725 & 0,752 & 0,736 & 0,666 \\
\hline $\mathrm{Na} \%$ & 0,244 & 0,244 & 0,214 & 0,214 & 0,205 & 0,194 \\
\hline $\mathrm{Cl} \%$ & 0,305 & 0,305 & 0,279 & 0,279 & 0,326 & 0,908 \\
\hline Рo \% & 0,846 & 0,836 & 0,794 & 0,783 & 0,734 & 0,676 \\
\hline
\end{tabular}

${ }^{1}$ Recomendações de Rostagno et al. (2005) (According to Rostagno et al., 2005).

2 Aminoácido do ovo desidratados segundo Norberg (2004) (Amino acid composition the dehydrated egg as by Norberg, 2004).

${ }^{3}$ Composição básica do produto (basic composition of product): sulfato de ferro (iron sulfate), sulfato de cobre (sulfate copper), óxido de zinco (zinc oxid), monóxido de manganês (manganese monoxide), selenito de sódio (sodium selenite), iodeto de cálcio (calcium iodate), veículo q.s.p. Níveis de garantia por kg do produto (Guaranty level per $\mathrm{kg}$ of product): $\mathrm{Mn}-140.000 \mathrm{mg}, \mathrm{Zn}-120.000 \mathrm{mg}$, Fe $-100.000 \mathrm{mg}, \mathrm{Cu}-18.000 \mathrm{mg}, \mathrm{I}-2.000 \mathrm{mg}$, Se $-600 \mathrm{mg}$.

${ }^{4}$ Níveis de garantia por $\mathrm{kg}$ do produto (Guaranty levels per $\mathrm{kg}$ of product): vit. A - 36.000.000 UI, vit. D3 - 7.400.000 UI, vit. E - $64.000 \mathrm{UI}$, vit. K3 - 8.000 mg, vit. B12 - $48.000 \mathrm{mg}$, vit. B1 $-6.400 \mathrm{mg}$, vit. B2 - $20.000 \mathrm{mg}$, vit. B6 - $9.600 \mathrm{mg}$, ácido fólico (folic acid) - $2.800 \mathrm{mg}$, ácido pantotênico (pantothenic acid) $44.000 \mathrm{mg}$, ácido nicotínico (nicotinic acid) - $120.000 \mathrm{mg}$, biotina (biotin) - $200 \mathrm{mg}$.

${ }^{5}$ Sulfaquinoxalina $24 \mathrm{~g}$, diaveridina $12 \mathrm{~g}$, trimetropim 4,8 g. Excipiente q.s.p. - $100 \mathrm{~g}$.

${ }^{6}$ Bacitracina de zinco (Zinc bacitracin).

7 BHT =Butil hdroxi tolueno.

8 Melbond (Lignosulfato).

9 Inerte = areia de construção (Building sand)

da composição de carcaça e do trato gastro intestinal. As partes analisadas foram os pesos do peito com pele, peito sem pele, peito com osso, filé de peito, Pectoralis major, Pectoralis minor, coxa, sobrecoxa, dorso e asa.

O rendimento de carcaça foi obtido em relação ao peso vivo, de modo que o peso de carcaça foi dividido pelo peso vivo e multiplicado por 100 . Os rendimentos dos cortes foram calculados em relação ao peso da carcaça. O filé de peito foi obtido manualmente por um único operador e, em seguida, o material foi separado em seus respectivos músculos, Pectoralis major e Pectoralis minor. Para análise do tratogastrintestinal, foram avaliados os pesos do proventrículo, da moela, do intestino delgado, do intestino grosso e da gordura abdominal. 
As análises estatísticas foram realizadas por meio do programa estatístico SAEG - Sistema para Análises Estatísticas e Genética (UFV, 1983), utilizando-se o teste $\mathrm{F}(\mathrm{P} \leq 0,05)$ para comparação das médias.

\section{Resultados e Discussão}

Houve efeito da interação ovo desidratado $\times$ forma física da ração $(\mathrm{P}<0,05)$ sobre o consumo de ração (diário e total) nos períodos de 1 a 2 e de 1 a 4 dias de idade (Tabela 2). Na ausência de ovo desidratado, a ração peletizada estimulou mais o consumo de ração (diário e total) nos períodos de 1 a 2 e de 1 a 4 dias $(P<0,05)$, entretanto, quando acrescido $0,5 \%$ de ovo desidratado, o consumo no período de 1 a 4 dias foi maior $(\mathrm{P}<0,05)$ quando fornecida a ração farelada. A inclusão de ovo desidratado na ração farelada estimulou o consumo diário apenas no período de 1 a 2 dias de idade. No entanto, sua inclusão na ração peletizada diminuiu $(\mathrm{P}<0,05)$ o consumo de ração (diário e total) tanto na fase de 1 a 2 como de 1 a 4 dias de idade. É possível que a peletização tenha elevado a densidade energética da ração contendo ovo desidratado afetando o consumo dos pintos.

A interação significativa $(\mathrm{P}>0,05)$ ovo desidratado $\times$ forma física da ração não influenciou o consumo de ração nos períodos de 1 a 7, 1 a 14, 1 a 21, 1 a 33 e de 1 a 42 dias de idade (Tabela 3 ).

A inclusão de $0,5 \%$ do ovo desidratado também não alterou $(\mathrm{P}>0,05)$ os consumos diário e total nas fases de 1 a 7, 1 a 14,1 a 21,1 a 33 e 1 a 42 dias de idade. Entretanto, a forma física da ração afetou $(\mathrm{P}<0,05)$ o consumo de ração na fase de 1 a 7 dias de idade, quando o consumo foi maior com a ração peletizada. Esse resultado corrobora o obtido por Zanotto et al. (1996), que verificaram aos 32 dias maior consumo de ração em aves alimentadas com ração peletizada. Roll et al. (1999) também observaram, até 32 dias de idade, maior consumo de ração peletizada em comparação à ração farelada.

Não houve influência $(\mathrm{P}>0,05)$ da interação níveis de ovo desidratado $\times$ forma física da ração sobre o peso vivo das aves (Tabela 4). A inclusão de ovo desidratado não afetou $(\mathrm{P}>0,05)$ o peso vivo das aves no $2 \underline{0}, 4^{\circ}$ e $33^{\circ}$ dias de idade. Ribeiro et al. (2006a), em experimento com pintos de corte, observaram que a inclusão desse alimento nas dietas também não afetou o desempenho das aves. Esses resultados sugerem a possibilidade de inclusão do ovo desidratado na dieta de frangos de corte como opção de aproveitamento dos ovos descartados diariamente nas granjas comerciais e na indústria do ovo líquido.

As aves alimentadas com a ração peletizada apresentaram maior peso vivo $(\mathrm{P}<0,05)$ em comparação àquelas alimentadas com a ração farelada. Esse resultado corrobora o observado por Brum et al. (1998), que verificaram melhor peso corporal em aves $(\mathrm{P}<0,01)$ alimentadas com rações trituradas no período de 22 a 35 dias de idade em comparação àquelas alimentadas com ração farelada. Vargas et al. (2001) observaram que o peso corporal aos 35 dias de idade de aves alimentadas com ração triturada foi superior ao daquelas alimentadas com ração farelada. Munt et al. (1995) também relataram que frangos alimentados com rações peletizadas apresentaram maior peso corporal em comparação aos que receberam dietas fareladas. Engberg et al. (2002) atribuíram o maior peso corporal de aves alimentadas

Tabela 2 - Consumos diário (CD) e total (CT) de pintos de corte alimentados com rações contendo ou não ovo desidratado e processadas em duas formas físicas em diferentes períodos de idade

Table 2 - Daily (DFI) and total (TFI) feed intake of broilers chicks fed diets containing or not dehydrated egg and processed in two physical form in different periods of age

\begin{tabular}{|c|c|c|c|c|c|c|c|c|}
\hline \multirow[t]{5}{*}{ Item } & \multicolumn{8}{|c|}{$\begin{array}{c}\text { Consumo de ração (g) } \\
\text { Feed intake }\end{array}$} \\
\hline & \multicolumn{2}{|c|}{1 a 2 dias } & \multicolumn{2}{|c|}{1 a 2 dias } & \multicolumn{2}{|c|}{1 a 4 dias } & \multicolumn{2}{|c|}{1 a 4 dias } \\
\hline & \multicolumn{2}{|c|}{ CD } & \multicolumn{2}{|c|}{$\mathrm{CT}$} & \multicolumn{2}{|c|}{ CD } & \multicolumn{2}{|c|}{$\mathrm{CT}$} \\
\hline & \multicolumn{2}{|c|}{$D F I$} & \multicolumn{2}{|c|}{ TFI } & \multicolumn{2}{|c|}{$D F I$} & \multicolumn{2}{|c|}{$T F I$} \\
\hline & \multicolumn{8}{|c|}{$\begin{array}{l}\text { Forma física } \\
\text { Physical form }\end{array}$} \\
\hline $\begin{array}{l}\text { Ovo desidratado (\%) } \\
\text { Dehydrated egg }\end{array}$ & $\begin{array}{l}\text { Farelada } \\
\text { Mash }\end{array}$ & $\begin{array}{l}\text { Peletizada } \\
\text { Pellet }\end{array}$ & $\begin{array}{l}\text { Farelada } \\
\text { Mash }\end{array}$ & $\begin{array}{l}\text { Peletizada } \\
\text { Pellet }\end{array}$ & $\begin{array}{l}\text { Farelada } \\
\text { Mash }\end{array}$ & $\begin{array}{l}\text { Peletizada } \\
\text { Pellet }\end{array}$ & $\begin{array}{l}\text { Farelada } \\
\text { Mash }\end{array}$ & $\begin{array}{l}\text { Peletizada } \\
\text { Pellet }\end{array}$ \\
\hline 0 & $8,6 \mathrm{Bb}$ & 9,3Аа & $17,1 \mathrm{Bb}$ & $18,6 \mathrm{Aa}$ & $15,4 \mathrm{Ab}$ & $16,1 \mathrm{Aa}$ & $61,7 \mathrm{Ab}$ & $64,2 \mathrm{Aa}$ \\
\hline 0,5 & $8,9 \mathrm{Ab}$ & $9,2 \mathrm{Ba}$ & $17,9 \mathrm{Ab}$ & $18,4 \mathrm{Ba}$ & $15,7 \mathrm{Aa}$ & $15,5 \mathrm{Bb}$ & $62,8 \mathrm{Aa}$ & $62,1 \mathrm{Bb}$ \\
\hline
\end{tabular}


Tabela 3 - Consumos diário (CD) e total (CT) de ração de pintos de corte alimentados com rações contendo ou não ovo desidratado e processadas em duas formas físicas em diferentes períodos de idade

Table 3 - Daily (DFI) and total (TFI) feed intake of broilers chicks fed diets containing or not dehydrated egg and processed in two physical form in different periods of age

\begin{tabular}{|c|c|c|c|c|c|c|c|c|c|c|}
\hline \multirow[t]{4}{*}{$\begin{array}{l}\text { Ovo desidratado (\%) } \\
\text { Dehydrated egg (\%) }\end{array}$} & \multicolumn{10}{|c|}{$\begin{array}{c}\text { Consumo de ração (g) } \\
\text { Feed intake }\end{array}$} \\
\hline & \multicolumn{2}{|c|}{1 a 7 dias } & \multicolumn{2}{|c|}{1 a 14 dias } & \multicolumn{2}{|c|}{1 a 21 dias } & \multicolumn{2}{|c|}{1 a 33 dias } & \multicolumn{2}{|c|}{1 a 42 dias } \\
\hline & CD & $\mathrm{CT}$ & CD & $\mathrm{CT}$ & CD & $\mathrm{CT}$ & CD & $\mathrm{CT}$ & CD & $\mathrm{CT}$ \\
\hline & $D F I$ & $T F I$ & $D F I$ & $T F I$ & $D F I$ & $T F I$ & $D F I$ & $T F I$ & $D F I$ & TFI \\
\hline 0 & 24,6 & 172,1 & 52,4 & 732,9 & 69,3 & 1454,3 & 99,1 & $3.271,3$ & 119,4 & $5.013,1$ \\
\hline 0,5 & 24,3 & 170,0 & 51,6 & 721,7 & 67,3 & 1413,7 & 98,3 & $3.244,2$ & 118,1 & $4.961,0$ \\
\hline $\begin{array}{l}\text { Forma física } \\
\text { Physical form }\end{array}$ & \multicolumn{10}{|c|}{$\begin{array}{l}\text { Consumo de ração (g) } \\
\text { Feed intake }\end{array}$} \\
\hline Farelada (Mash) & $24,1 \mathrm{~B}$ & $168,8 \mathrm{~B}$ & 51,4 & 718,9 & 67,75 & $1.422,8$ & 98,0 & $3.235,7$ & 117,0 & $4.915,3$ \\
\hline Peletizada (Pellet) & $24,8 \mathrm{~A}$ & $173,3 \mathrm{~A}$ & 52,5 & 735,6 & 68,81 & $1.445,0$ & 99,4 & $3.280,2$ & 120,5 & $5.058,9$ \\
\hline CV (\%) & \multicolumn{2}{|c|}{5,28} & \multicolumn{2}{|c|}{7,16} & \multicolumn{2}{|c|}{6,61} & \multicolumn{2}{|c|}{7,02} & & 6,87 \\
\hline
\end{tabular}

A,B Médias seguidas de letras maiúsculas diferentes na coluna diferem pelo teste $F$.

$A, B$ Means followed by different capital letter in the column are different by F test.

Tabela 4 - Peso vivo de pintos de corte alimentados com rações contendo ou não ovo desidratado e processadas em duas formas físicas aos 2, 4 e 33 dias de idade

Table 4 - Body weight of broilers chicks fed diets containing or not dehydrated egg and processed in two physical form at 2, 4 and 33 days of age

\begin{tabular}{lccc}
\hline Item & \multicolumn{3}{c}{$\begin{array}{c}\text { Peso vivo } \\
\text { Body weight }\end{array}$} \\
\cline { 2 - 4 } Ovo desidratado (\%) & \multicolumn{3}{c}{ Dia } \\
Dehydrated egg & \multicolumn{3}{c}{ Day dia } \\
\cline { 2 - 4 } & $2^{\text {2o dia }}$ & $33^{\text {o }}$ dia \\
& $2^{\text {nd }}$ day & $4^{\text {th }}$ day & 3 day \\
\hline 0 & 67,74 & 109,13 & $2.039,13$ \\
0,5 & 67,77 & 109,30 & $2.025,76$ \\
\hline
\end{tabular}

Forma física

Physical form

\begin{tabular}{lrrr}
\hline $\begin{array}{l}\text { Farelada } \\
\text { Mash }\end{array}$ & $65,97 \mathrm{~B}$ & $106,90 \mathrm{~B}$ & $1.988,39 \mathrm{~B}$ \\
$\begin{array}{l}\text { Peletizada } \\
\text { Pellet }\end{array}$ & $69,54 \mathrm{~A}$ & $111,53 \mathrm{~A}$ & $2.076,49 \mathrm{~A}$ \\
CV $(\%)$ & 2,182 & 2,315 & 3,833 \\
\hline
\end{tabular}

A,B Médias seguidas de letras maiúsculas diferentes na coluna diferem pelo teste $F$.

A,B Means followed by different capital letter in the column differ by $F$ test.

com dieta peletizada ao maior consumo e à melhor utilização dos nutrientes em comparação a aves alimentadas com rações fareladas.

Constatou-se (Tabela 5) efeito de interação $(\mathrm{P}<0,05)$ entre a inclusão de ovo desidratado (fornecido até 21 dias) e a forma física da ração sobre o peso vivo aos 7, 14, 21 e 42 dias de idade. Independentemente da inclusão de ovo desidratado, a peletização da ração melhorou o peso vivo dos frangos em todos os períodos estudados. Na ração farelada, a inclusão de $0,5 \%$ de ovo desidratado aumentou de forma significativa $(\mathrm{P}<0,05)$ o peso vivo dos frangos aos 7, 21 e 42 dias de idade. Entretanto, a inclusão de ovo desidratado na ração peletizada piorou $(\mathrm{P}<0,05)$ o peso vivo das aves aos 7 dias de idade, porém, não teve efeito no período de 14 a 21 dias e apenas efeito indireto sobre o peso vivo aos 42 dias de idade. Esses resultados indicam que a inclusão de ovo desidratado somente melhora o peso vivo de frangos alimentados com rações fareladas. As razões para o peso vivo não ter sido alterado até os 42 dias de idade nas aves alimentadas com rações peletizadas contendo ovo desidratado não puderam ser esclarecidas.

O ganho de peso nos períodos de 1 a 2,1 a 4,1 a 14 , 1 a 21 e 1 a 33 dias de idade não foi afetado $(\mathrm{P}>0,05)$ pela interação dos níveis de inclusão de ovo desidratado e a forma física da ração. A inclusão do ovo desidratado nas rações não alterou o ganho de peso de frangos de corte, entretanto, a ração peletizada aumentou $(\mathrm{P}<0,05)$ o ganho de peso nos períodos de 1 a $2(+16,5 \%), 1$ a $4(+7,4 \%), 1$ a $14(+6,5 \%)$ e 1 a 21 dias de idade (+ 5,9\%) em comparação à ração farelada.

De acordo com Roll (1999), até os 21 dias de idade, frangos alimentados com dietas trituradas apresentam, em média, ganho de peso $2,8 \%$ superior ao daqueles alimentados com ração farelada.

Houve efeito $(\mathrm{P}<0,05)$ da interação ovo desidratado $\times$ forma física da ração sobre o ganho de peso nos períodos de 1 a 7 e de 1 a 42 dias de idade (Tabela 7). A ração peletizada aumentou $(\mathrm{P}<0,05)$ o ganho de peso das aves nas fases de 1 a 7 e de 1 a 42 dias de idade, independentemente da presença de ovo desidratado. Por outro lado, a adição de ovo desidratado à ração farelada melhorou o ganho de peso das aves nas fases de 1 a 7 e de 1 a 42 dias de idade 
Tabela 5 - Peso vivo de pintos de corte alimentados com rações contendo ou não ovo desidratado e processadas em duas formas físicas aos $7,14,21$ e 42 dias de idade

Table 5 - Body weight of broiler chicks fed diets containing or not dehydrated egg and processed in two physical form at 7, 14, 21 and 42 days of age

\begin{tabular}{|c|c|c|c|c|c|c|c|c|}
\hline \multirow[t]{3}{*}{ Item } & \multicolumn{8}{|c|}{$\begin{array}{l}\text { Peso vivo } \\
\text { Body weight }\end{array}$} \\
\hline & \multicolumn{2}{|c|}{7 dias } & \multicolumn{2}{|c|}{14 dias } & \multicolumn{2}{|c|}{21 dias } & \multicolumn{2}{|c|}{42 dias } \\
\hline & \multicolumn{8}{|c|}{$\begin{array}{l}\text { Forma física } \\
\text { Physical form }\end{array}$} \\
\hline $\begin{array}{l}\text { Ovo desidratado (\%) } \\
\text { Dehydrated egg }\end{array}$ & $\begin{array}{c}\text { Farelada } \\
\text { Mash }\end{array}$ & $\begin{array}{l}\text { Peletizada } \\
\text { Pellet }\end{array}$ & $\begin{array}{l}\text { Farelada } \\
\text { Mash }\end{array}$ & $\begin{array}{c}\text { Peletizada } \\
\text { Pellet }\end{array}$ & $\begin{array}{l}\text { Farelada } \\
\text { Mash }\end{array}$ & $\begin{array}{c}\text { Peletizada } \\
\text { Pellet }\end{array}$ & $\begin{array}{l}\text { Farelada } \\
\text { Mash }\end{array}$ & $\begin{array}{c}\text { Peletizada } \\
\text { Pellet }\end{array}$ \\
\hline 0 & $179,0 \mathrm{Bb}$ & $193,9 \mathrm{Aa}$ & $485,1 \mathrm{Ab}$ & $521,7 \mathrm{Aa}$ & $921,1 \mathrm{Bb}$ & $988,1 \mathrm{Aa}$ & $2.616,5 \mathrm{Bb}$ & $2.759,0 \mathrm{Aa}$ \\
\hline 0,5 & $182,7 \mathrm{Ab}$ & $189,4 \mathrm{Ba}$ & $492,0 \mathrm{Ab}$ & $515,8 \mathrm{Aa}$ & $934,5 \mathrm{Ab}$ & $972,4 \mathrm{Aa}$ & $2.683,9 \mathrm{Ab}$ & $2.711,2 \mathrm{Aa}$ \\
\hline
\end{tabular}

$\overline{\mathrm{A}, \mathrm{B}}$ Médias seguidas de letras maiúsculas diferentes na coluna diferem pelo teste $\mathrm{F}$.

a,b Médias seguidas de letras minúsculas diferentes na linha diferem pelo teste $F$.

A,B Means followed by different capital letter in the column are different by F test.

a,b Means followed by different small letter in row are different by $F$ test.

Tabela 6 - Ganho de peso diário e total de pintos de corte alimentados com rações contendo ou não ovo desidratado e processadas em duas formas físicas em diferentes períodos de idade

Table 6 - Daily and total weight gain of broiler chicks fed diets containing or not dehydrated egg and processed in two physical form in different periods of age

Ovo desidratado (\%)

Dehydrated egg

Ganho de peso diário (g)

Daily weight gain

\begin{tabular}{cccccc} 
& 1 a 2 dias & 1 a 4 dias & 1 a 14 dias & 1 a 21 dias & 1 a 33 dias \\
\hline 0,0 & 12,1 & 16,4 & 32,8 & 43,4 & 60,5 \\
0,5 & 12,1 & 16,4 & 32,9 & 43,3 & 60,1
\end{tabular}

Forma física

Physical form

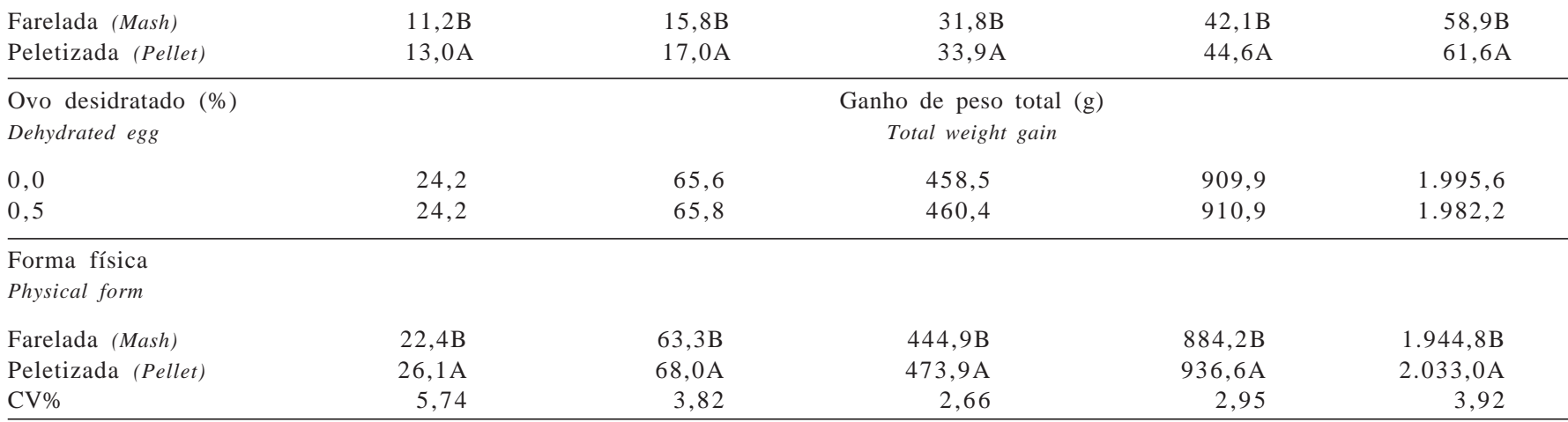

A,B Médias seguidas de letras maiúsculas diferentes na coluna diferem pelo teste $F$.

$A, B$ Means followed by different capital letter in the column differ by $F$ test.

$(\mathrm{P}<0,05)$, enquanto a ração peletizada com ovo desidratado piorou o ganho de peso no período de 1 a 7 dias $(\mathrm{P}<0,05)$, mas não teve efeito no período 1 a 42 dias de idade $(\mathrm{P}>0,05)$.

Ribeiro et al. (2006a) também constataram que a adição de ovo desidratado na ração farelada melhorou o peso vivo de pintinhos nas primeiras horas de vida. Silva et al. (2006) observaram que a adição de $0,6 \%$ de ovo desidratado na dieta pré-inicial farelada estimulou o desempenho das pintainhas em relação à dieta farelada sem ovo desidratado. Portanto, a inclusão de ovo desidratado em rações fareladas parece estimular mais o ganho de peso que sua adição em rações peletizadas.

Não houve efeito $(P>0,05)$ da interação nível de ovo desidratado $\times$ forma física da ração sobre a conversão alimentar dos frangos nos períodos de 1 a 2, 1 a 4, 1 a 7, 1 a 14,1 a 21,1 a 33 e 1 a 42 dias de idade (Tabela 8).

$\mathrm{O}$ ovo desidratado não afetou $(\mathrm{P}>0,05)$ a conversão alimentar, mas proporcionou melhores conversões, em valores absolutos, nos períodos de 1 a 7, 1 a 21 e de 1 a 42 dias de idade (1,0; 2,8 e 1,5\%, respectivamente). Em todos os períodos avaliados, a conversão foi melhor nos frangos 
Tabela 7 - Ganho de peso diário e total de frangos de corte alimentados com rações contendo ou não ovo desidratado e processadas em duas formas físicas nos períodos de 1 a 7 e de 1 a 42 dias de idade

Table 7 - Daily and total weight gain of broiler chicks fed diets containing or not dehydrated egg and processed in two physical form in the periods from 1 to 7 and 1 to 42 days of age

Ovo desidratado (\%) $\quad$ Ganho de peso
$\begin{aligned} & \text { Wehydrated egg } \\ & \text { Weint }\end{aligned}$

Dehydrated egg

1 a 7 dias (1-7 days)

Ganho de peso diário Ganho de peso total Daily weight gain

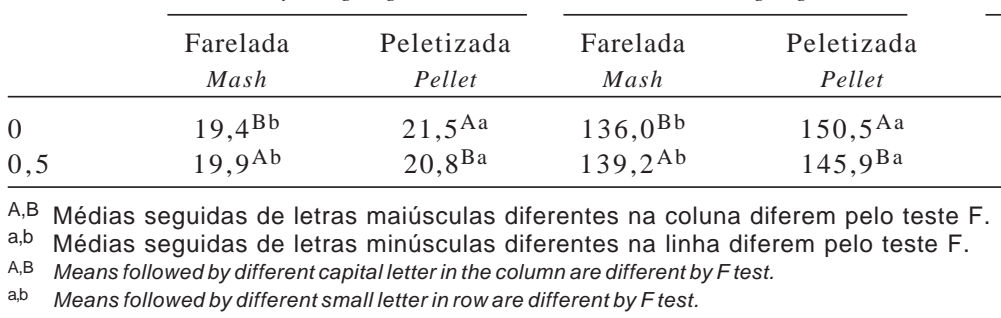

Tabela 8 - Conversão alimentar de pintos de corte alimentados com rações contendo ou não ovo desidratado e processadas em duas formas físicas em diferentes períodos de idade

Table 8 - Feed:gain ratio of broiler chicks fed diets containing or not dehydrated egg and processed in two physical form in different periods of age

\begin{tabular}{|c|c|c|c|c|c|c|c|}
\hline \multirow[b]{3}{*}{ OD\% (DEGG) } & \multicolumn{7}{|c|}{$\begin{array}{c}\text { Conversão alimentar (CA) } \\
\text { Feed:gain ratio (FGR) }\end{array}$} \\
\hline & \multicolumn{7}{|c|}{ Idade, dias (Age, days) } \\
\hline & $1-2$ & $1-4$ & $1-7$ & $1-14$ & $1-21$ & $1-33$ & $1-42$ \\
\hline 0 & 0,747 & 0,961 & 1,206 & 1,601 & 1,599 & 1,642 & 1,898 \\
\hline 0,5 & 0,763 & 0,956 & 1,194 & 1,570 & 1,555 & 1,638 & 1,870 \\
\hline \multicolumn{8}{|c|}{ Forma física (Physical form) } \\
\hline Farelada (Mash) & $0,800^{\mathrm{A}}$ & $0,985^{\mathrm{A}}$ & $1,261^{\mathrm{A}}$ & $1,654^{\mathrm{A}}$ & $1,635^{\mathrm{A}}$ & $1,688^{\mathrm{A}}$ & $1,941^{\mathrm{A}}$ \\
\hline Peletizada (Pellet) & $0,710^{\mathrm{B}}$ & $0,934^{\mathrm{B}}$ & $1,139^{\mathrm{B}}$ & $1,5173^{\mathrm{B}}$ & $1,519^{\mathrm{B}}$ & $1,592^{\mathrm{B}}$ & $1,827^{\mathrm{B}}$ \\
\hline CV (\%) & 6,996 & 5,695 & 5,764 & 7,425 & 6,892 & 7,090 & 6,884 \\
\hline
\end{tabular}

A,B Médias seguidas de letras maiúsculas diferentes na coluna diferem pelo teste $F$.

$A, B$ Means followed by different capital letter in the column are different by Ftest.

alimentados com a ração peletizada $(\mathrm{P}<0,05)$, nos quais foram obtidas conversões 11,2 (1 a 2 dias de idade) e 5,9\% (1 a 4 dias de idade) melhores em relação à encontrada com ração farelada. Vargas et al. (2001) constataram que frangos de 21 a 35 dias de idade apresentaram melhor conversão alimentar quando alimentados com ração triturada em comparação à ração farelada. Turner (1995) também observou melhor desempenho de frangos alimentados com rações peletizadas e atribuíram esse resultado ao aumento da densidade de nutrientes da ração e às reduções do pó e do gasto energético no consumo de ração pelas aves. O autor comentou que a peletização pode melhorar em $10 \%$ o ganho de peso e em $5 \%$ a conversão alimentar de frangos de corte. Segundo Leeson \& Summers (1991), a peletização da ração diminui as atividades motoras relacionadas à ingestão de ração como conseqüência do menor tempo de cada refeição, reduzindo o gasto de energia com mantença.

Segundo Roll et al. (1999), no intervalo de 22 a 46 dias, a pior conversão alimentar foi observada nas aves alimentadas com ração farelada.

Ao contrário dos resultados obtidos por Junqueira et al. (2001), a inclusão de ovo desidratado nas rações não prejudicou o desempenho das aves. Portanto, considerando o alto valor nutricional do ovo e o grande volume de ovos trincados e quebrados diariamente nas granjas e que normalmente não são empregados na alimentação humana, o ovo desidratado pode se tornar uma alternativa viável como ingrediente na formulação de rações para aves.

A peletização de rações tem sido utilizada como forma de melhorar a eficiência de utilização dos nutrientes e 
aumentar o ganho de peso. Os resultados deste trabalho corroboram a afirmação de que a peletização melhora o desempenho de frangos de corte.

Não foi observado efeito $(\mathrm{P}>0,05)$ da interação entre os dois principais fatores estudados sobre o rendimento dos cortes estudados (Tabela 9). A inclusão do ovo desidratado e a forma física da ração não influenciaram o peso e o rendimento de carcaça e dos cortes $(\mathrm{P}>0,05)$, exceto o rendimento de coxa, que foi maior $(\mathrm{P}<0,05)$ nas aves alimentadas com a ração farelada. Esse resultado corrobora a afirmação de que a forma física da ração não afeta o rendimento de carcaça de frangos de corte (López \& Baião, 2002).

Para os rendimentos de peito com e sem pele, Pectoralis minor e filé de peito, foram observadas interações significativas $(\mathrm{P}<0,05)$ entre os fatores principais estudados neste trabalho (Tabela 10). A inclusão de ovo desidratado não influenciou nenhuma variável quando a ração foi fornecida na forma farelada ( $\mathrm{P}>0,05)$, contudo, o peso do Pectoralis minor reduziu $(\mathrm{P}<0,05)$ com a inclusão do ovo desidratado na ração peletizada (Tabela 10). A peletização da ração sem a inclusão do ovo desidratado melhorou de forma significativa $(\mathrm{P}<0,05)$ os pesos de peito (com e sem pele), Pectoralis minor e filé de peito.

O peso do trato gastrointestinal diminuiu $(\mathrm{P}<0,05)$ com a inclusão de ovo desidratado na ração peletizada. Esse resultado contraria, em parte, a observação de Junqueira et al. (2001), que não constataram alteração do peso e do
Tabela 10 - Composição da carcaça de pintos de corte alimentados com rações contendo ou não ovo desidratado e processadas em duas formas físicas

Table 10 - Carcass composition of broiler chicks fed diets containing or not dehydrated egg and processed in two physical form

\begin{tabular}{|c|c|c|}
\hline \multirow[b]{2}{*}{$\begin{array}{l}\text { Ovo desidratado (\%) } \\
\text { Dehydrated egg }\end{array}$} & \multicolumn{2}{|c|}{$\begin{array}{l}\text { Forma física } \\
\text { Physical form }\end{array}$} \\
\hline & $\begin{array}{l}\text { Farelada } \\
\text { Mash }\end{array}$ & $\begin{array}{l}\text { Peletizada } \\
\text { Pellet }\end{array}$ \\
\hline \multicolumn{3}{|l|}{$\begin{array}{l}\text { Peito com pele (\%) } \\
\text { Breast with skin }\end{array}$} \\
\hline $\begin{array}{l}0 \\
0,5\end{array}$ & $\begin{array}{l}682,9^{\mathrm{Ab}} \\
704,1^{\mathrm{Aa}}\end{array}$ & $\begin{array}{l}727,3^{\text {Аа }} \\
702,5^{\text {Аа }}\end{array}$ \\
\hline \multicolumn{3}{|l|}{$\begin{array}{l}\text { Peito sem pele (\%) } \\
\text { Breast without skin }\end{array}$} \\
\hline $\begin{array}{l}0,0 \\
0,5\end{array}$ & $\begin{array}{l}638,2^{\mathrm{Ab}} \\
660,6^{\mathrm{Aa}}\end{array}$ & $\begin{array}{l}681,5^{\text {Аа }} \\
657,9^{\text {Аа }}\end{array}$ \\
\hline \multicolumn{3}{|l|}{ P. minor $(\%)$} \\
\hline $\begin{array}{l}0,0 \\
0,5\end{array}$ & $\begin{array}{l}220,5^{\mathrm{Ab}} \\
226,1^{\mathrm{Aa}}\end{array}$ & $\begin{array}{l}237,1^{\mathrm{Aa}} \\
217,6^{\mathrm{Ba}}\end{array}$ \\
\hline \multicolumn{3}{|l|}{$\begin{array}{l}\text { Filé de peito (\%) } \\
\text { Breast fillet }\end{array}$} \\
\hline $\begin{array}{l}0,0 \\
0,5\end{array}$ & $\begin{array}{l}530,6^{\mathrm{Ab}} \\
551,0^{\mathrm{Aa}}\end{array}$ & $\begin{array}{l}570,6^{\mathrm{Aa}} \\
550,9^{\mathrm{Aa}}\end{array}$ \\
\hline \multicolumn{3}{|c|}{$\begin{array}{l}\text { Trato gastrointestinal (g) } \\
\text { Gastrointestinal tract }\end{array}$} \\
\hline $\begin{array}{l}0,0 \\
0,5\end{array}$ & $\begin{array}{l}166,65^{\mathrm{Aa}} \\
176,31^{\mathrm{Aa}}\end{array}$ & $\begin{array}{l}173,62^{\mathrm{Aa}} \\
161,81^{\mathrm{Ab}}\end{array}$ \\
\hline $\begin{array}{l}\mathrm{A}, \mathrm{B} \text { Médias seguidas d } \\
\text { pelo teste } \mathrm{F} . \\
\mathrm{a,b} \text { Médias seguidas de } \\
\text { teste } \mathrm{F} \text {. } \\
\mathrm{A}, \mathrm{B} \text { Means followed by diffe } \\
\text { a,b Means followed by diffe }\end{array}$ & $\begin{array}{l}\text { as maiúscula } \\
\text { s minúsculas } \\
\text { apital letter in th } \\
\text { mall letter in ron }\end{array}$ & $\begin{array}{l}\text { na coluna diferem } \\
\text { linha diferem pelo } \\
\text { erent by F test. } \\
\text { Ftest. }\end{array}$ \\
\hline
\end{tabular}

Tabela 9 - Composição da carcaça de pintos de corte alimentados com rações contendo ou não ovo desidratado e processadas em duas formas físicas

Table 9 - Carcass composition of broiler chicks fed diets containing or not dehydrated egg and processed in two physical form

\begin{tabular}{|c|c|c|c|c|c|}
\hline & \multicolumn{2}{|c|}{$\begin{array}{c}\text { Ovo desidratado (\%) } \\
\text { Dehydrated egg }\end{array}$} & \multicolumn{2}{|c|}{$\begin{array}{l}\text { Forma física } \\
\text { Physical form }\end{array}$} & \multirow[t]{2}{*}{ CV (\%) } \\
\hline & 0 & 0,5 & $\begin{array}{l}\text { Farelada } \\
\text { Mash }\end{array}$ & $\begin{array}{c}\text { Peletizada } \\
\text { Pellet }\end{array}$ & \\
\hline Carcaça (g) (Carcass) & $2.149,39$ & $2.131,06$ & $2.111,47$ & $2.168,97$ & 5,997 \\
\hline Carcaça (\%) (Carcass) & 83,34 & 83,30 & 82,82 & 83,82 & 3,744 \\
\hline Peito com pele (\%) (Breast with skin) & 32,81 & 33,02 & 32,88 & 32,95 & 3,903 \\
\hline Сoxa (\%) (Thigh) & 12,68 & 12,47 & $12,72 \mathrm{a}$ & $12,41 b$ & 5,206 \\
\hline Sobrecoxa (g) (Drumstick) & 334,72 & 334,15 & 333,50 & 335,38 & 8,612 \\
\hline Sobrecoxa (\%) (Drumstick) & 15,57 & 15,71 & 15,81 & 15,47 & 7,591 \\
\hline Dorso (g) (Back) & 506,47 & 504,19 & 499,39 & 511,27 & 7,314 \\
\hline Dorso (\%) (Back) & 23,56 & 23,69 & 23,67 & 23,58 & 5,233 \\
\hline Filé de peito (\%) (Breast fillet) & 25,63 & 25,87 & 25,65 & 25,85 & 5,329 \\
\hline P. minor (\%) & 10,66 & 10,42 & 10,59 & 10,48 & 8,468 \\
\hline
\end{tabular}

a,b Médias seguidas de letras minúsculas diferentes na linha diferem pelo teste $\mathrm{F}$.

a,b Means followed by different small letter in row are statistically different by $F$ test. 
comprimento do intestino ao fornecerem ovo desidratado nos níveis 5, 10, 15, 20 e 25\% da ração. Do mesmo modo, Choi et al. (1986) verificaram maior peso do trato gastrointestinal em frangos com 8 semanas de idade alimentados com dietas fareladas em relação aos alimentados com dietas granuladas.

Não foi observada interação dos fatores estudados $(\mathrm{P}>0,05)$ sobre o peso dos órgãos digestivos e da gordura abdominal (Tabela 11). Não ocorreu efeito significativo do ovo desidratado sobre os órgãos do aparelho digestivo e sobre a gordura abdominal $(\mathrm{P}>0,05)$, mas a forma física afetou os pesos de proventrículo, moela e intestino delgado; a ração peletizada proporcionou maior peso do proventrículo e do intestino delgado em comparação aos pesos destas variáveis observadas em frangos alimentados com ração farelada. No entanto, a ração farelada promoveu maior peso da moela em comparação à dieta peletizada.

Esse resultado confirma o observado por López \& Baião (2004) que constataram que frangos alimentados com ração farelada apresentaram maior peso de moela em relação aos alimentados com rações peletizadas. Nir et al. (1995) e Engberg et al. (2002) observaram menor peso da moela em frangos alimentados com rações granuladas em comparação aos alimentados com rações fareladas. Esse fato pode ser atribuído à maior taxa de passagem das rações granuladas, o que provocaria menor volume de alimento retido e menor atividade dos músculos da moela (Macari et al., 1994; López \& Baião, 2002) ou maior retenção do alimento no papo, que escaparia mais tarde para o intestino delgado passando transitoriamente pela moela com a oferta da ração peletizada.

O aumento do peso do intestino delgado explica, em parte, o melhor desempenho dos frangos alimentados com rações peletizadas, uma vez que a maioria dos processos de digestão e absorção ocorre nesta porção do trato gastrointestinal.

A peletização da ração, independentemente da inclusão de ovo desidratado, altera a dinâmica de trânsito de ração pelo trato gastrintestinal. Enquanto na forma granulada a ração escaparia e ficaria retida no intestino, na forma farelada ficaria retida mais tempo na moela. Então, a ração peletizada estimularia maior crescimento intestinal em frangos e proporcionaria maiores ganho de peso e melhores conversões em comparação com rações fareladas.

Tabela 11 - Peso dos órgãos digestivos e da gordura abdominal de pintos de corte com rações contendo ou não ovo desidratado e processadas em duas formas físicas

Table 11 - Weight of the digestive organs and abdominal fat of broiler chicks fed diets containing or not dehydrated egg and processed in two physical form Orgãos digestivos e gordura abdominal (g) Digestive organs and abdominal fat

\begin{tabular}{lccccc}
$\begin{array}{l}\text { Ovo desidratado (\%) } \\
\text { Dehydrated egg }\end{array}$ & $\begin{array}{c}\text { Proventrículo } \\
\text { Proventriculus }\end{array}$ & $\begin{array}{c}\text { Moela } \\
\text { Gizzard }\end{array}$ & $\begin{array}{c}\text { Intestino delgado } \\
\text { Small intestine }\end{array}$ & $\begin{array}{c}\text { Intestino grosso } \\
\text { Large intestine }\end{array}$ & $\begin{array}{c}\text { Gordura abdominal } \\
\text { Abdominal fat }\end{array}$ \\
\hline 0 & 10,65 & 48,18 & 68,64 & 17,07 & 31,77 \\
0,5 & 10,16 & 47,67 & 68,65 & 17,36 & 30,51
\end{tabular}

Forma física

Physical form

Farelada (Mash)

Peletizada (Pellet)

$\mathrm{CV}(\%)$

$\begin{array}{rll}9,75^{\mathrm{B}} & 55,09^{\mathrm{A}} & 65,58^{\mathrm{B}} \\ 11,05^{\mathrm{A}} & 40,77^{\mathrm{B}} & 71,72^{\mathrm{A}} \\ 18,805^{15,009} & 13,318\end{array}$

$71,72^{\mathrm{A}}$
13,318

\section{7,35 \\ 17,09}

13,175
30,95

31,33

20,329

$A, B$ Médias seguidas de letras maiúsculas diferentes na coluna diferem pelo teste $F$.

$\mathrm{A}, \mathrm{B}$ Means followed by different capital letter in the column are statistically different by $F$ test.

\section{Conclusões}

A inclusão de $0,5 \%$ de ovo desidratado em rações préinicial e inicial não interfere no desempenho de frangos de corte aos 42 dias de idade. A ração peletizada melhora o desempenho de frangos de corte no período de 1 a 42 dias de idade. A peletização melhora as porcentagens dos cortes nobres peito com e sem pele, Pectoralis minor e filé de peito e aumenta os pesos do proventrículo e do intes- tino delgado, enquanto a ração farelada aumenta o peso da moela.

\section{Agradecimento}

À Empresa Guaraves Alimentos Ltda; à Melbar Produtos de Lignina Ltda; e à CAPES (Coordenação de Aperfeiçoamento de Pessoal de Nível Superior), pelo apoio financeiro. 


\section{Literatura Citada}

BRUM, P.A.R.; LIMA, G.J.M.; MAZZUCO, H. et al. Efeito do nível de trigo na dieta, percentual de grãos germinados e a forma física da ração sobre o desempenho de frangos de corte. In: CONFERÊNCIA APINCO 1998 DE CIÊNCIA E TECNOlOGiA AVÍCOlAs, Campinas. Anais... Campinas: Fundação Apinco de Ciência e Tecnologia Avícolas, 1998. p.10.

CHOI, J.H.; SO, B.S.; RYU, K.S. et al. Effects of pelleted or crumbled diets on the performance and the development of the digestive organs of broilers. Poultry Science, v.65, p.594-597, 1986.

DIBNER, J.J. Early development of the digestive tract and nutritional implications. Poultry Digest, v.5, p.16-19, 1997.

ENGBERG, R.M.; HEDEMANN, M.S.; JENSEN, B.B. et al. The influence of grinding and pelleting of feed on the microbial composition and activity in the digestive tract of broiler chickens. British Poultry Science, v.43, p.569-579, 2002.

JUNQUEIRA, O.M.; ARAÚJO, L.F.; ARAÚJO, C.S.S. et al. Desempenho de Frango de corte alimentados com ovo em pó. Revista Brasileira de Ciência Avícola, v.3, n.1, p.65-73, 2001.

LEESON S.; SUMMERS, J.D. Commercial poultry nutrition. Guelph: University Books, 1991. 350p.

LÓPEZ, C.A.A.; BAIÃO, N.C. Efeitos do tamanho da partícula e da forma física da ração sobre o desempenho, rendimento de carcaça e peso dos órgãos digestivos de frangos de corte. Arquivo Brasileiro Medicina Veterinária e Zootecnia, v.56, p.214221, 2004.

MACARI, M.; FURLAN, R.L.; GONZALES, E. Fisiologia aviária aplicada a frangos de corte. Jaboticabal: FUNEP- UNESP, 1994. 296p.

McCAPES, R.H.; EKPERIGIN, H.E.; CAMERON, W.J. et al. Effect of a new pelleting process on the level of contamination of poultry mash by Escherichia coli and Salmonella ssp. Avian Disease, v.33, p.103-111, 1989.

MINISTÉRIO DA AGRICULTURA. SECRETARIA NACIONAL DE DEFESA AGROPECUÁRIA. LABORATÓRIO NACIONAL DE REFERENCIA ANIMAL - LANARA. Métodos analíticos Oficiais para controle de produtos de origem animal e seus ingredientes - II - Métodos físicos e químicos. Brasília: 1981. p.1-2.

MORAN, E.T. Pelleting affects feed and its consumption. Poultry Science, v.5 p.30-31, 1987.

MUNT, R.H.C.; DINGLE, J.G.; SUMPAM, G. et al. Growth, carcass composition and profitability of meat chicks given pellets, mash or free-choice diets. British Poultry Science, v.36, p.277-284, 1995.

NILIPOUR, A. La peletización mejora el desempeño. Indústria avícola, v.39, p.42-46, 1993.
NIR, I.; HILLEL, R.; PTICHI, I. Effect of particle size on performance: 3. Grinding pelleting interactions. Poultry Science, v.74, p.771-783, 1995.

NORBERG, S.E.; DILGER, R.N.; DONG, H. et al. Utilization of energy and amino acids of spray-dried egg, plasma protein and soybean meal by ducks. Poultry Science, v.83, p.939-945, 2004.

NOY, I.; SKLAN, D. Yolk and exogenous feed utilization in the posthatch chick. Poultry Science, v.80, p.1490-495, 2001.

RIBEIRO, M.L.G.; SILVA, J.H.V.; FERNANDES, A.C. et al. Efeito do tempo de jejum pós-alojamento e inclusão do ovo desidratado em dietas pré-iniciais e iniciais de pintos de corte. Revista Brasileira de Ciência e Tecnologia Avícola, v.8, p.132, 2006a.

RIBEIRO, M.L.G.; SILVA, J.H.V.; TEIXEIRA, E.N.M. et al. Inclusão do ovo desidratado em dietas de frangos de corte de 1 a 21 dias de idade. Revista Brasileira de Ciência e Tecnologia Avícola, v.8, p.131, 2006b.

ROLL, V.F.B.; AVILA, V.S.; RUTZ, F. et al. Efeito da forma física da ração em frangos de corte durante o verão, Revista Brasileira de Agrociência, v.5, p.54-59, 1999.

ROSTAGNO, H.S.; ALBINO, L.F.T.; DONZELE, J.L. et al. Tabelas brasileiras para suínos e aves: composição de alimentos e exigências nutricionais. Viçosa, MG: Universidade Federal de Viçosa, 2005. 186p.

SILVA, J.H.V.; JORDÃO FILHO, J.; SILVA, E.L. et al. Efeito da substituição dos antimicrobianos pelo ovo desidratado na fase préinicial de frangas de dois grupos genéticos alojadas em camas nova e reciclada. Revista Brasileira de Zootecnia, v.35, p.2077-2084, 2006

TEIXEIRA, E.N.M.; SILVA, J.H.V.; BARROS, L.R. et al. Valor nutritivo do ovo desidratado e do caldo de cana para pintos. Revista Brasileira de Ciência e Tecnologia Avícola, v.7, p.130, 2005.

TURNER, R. Achieving optimum pellet quality. Feed Management, v.46, p.30-33, 1995.

UNIVERSIDADE FEDERAL DE VIÇOSA - UFV. SAEG - Sistema para analise estatística e genética. Viçosa, MG: 1983. 59p.

VARGAS, G.D.; BRUM, P.A.R.; FIALHO, F.B. et al. Efeito da forma física da ração sobre o desempenho de frangos de corte machos. Revista Brasileira de Agrociência, v.7, p.42-45, 2001.

ZANOTO, D.L.; BRUM, P.A.R.; GUIDONI, A.L. et al Granulometria do milho da dieta e desempenho de frangos de corte. In: CONFERÊNCIA APINCO'96 DE CIÊNCIA E TECNOlogia AVÍCOlAS, 1996, São Paulo. Anais... São Paulo: Fundação Apinco de Ciência e Tecnologia Avícola, 1996 p.19. 